\title{
NOSOTRAS, ENTRE DEFENDER LO PROPIO Y AVANZAR A LA AMPLITUD: FEMINISMO, IZQUIERDA Y DEMOCRACIA EN EL URUGUAY DE LOS 80
}

Defending a space of our own or working to widen our base: Feminism, the left and democracy in Uruguay in the 80's

Ana Laura de Giorgi'

\begin{abstract}
Resumen
Este artículo tiene por objetivo principal reconstruir la historia del feminismo de izquierda en el Uruguay de los ochenta, focalizando el análisis en la tensión que atravesó a estas iniciativas respecto a las estrategias y sus prácticas políticas. Este texto describe y analiza el campo de posibilidades delineado por las altas expectativas con la política democrática que incentivaron un feminismo "bien comportado" y el pasaje hacia algunas irreverencias o el repliegue hacia espacios que no lograban ser fácilmente politizados por parte de quienes se habían emancipado en el espacio público. Esta revisita a aquellos años no es sólo un modo de narrar la historia del feminismo del sur, también es una oportunidad para revisitar un proceso que ilumina debates actuales sobre la autonomía y las prácticas de los movimientos en el marco de las democracias del sur.
\end{abstract}

Palabras clave: Feminismo, Izquierda, Uruguay, Años Ochenta, Democracia

\begin{abstract}
The main objective of this article is to reconstruct the history of leftist feminism in the Uruguay of the 1980s, focusing analysis on the tension about strategies and political practices. This text analyzes the field of possibilities outlined by the high expectations with the democratic politics that stimulated a "well behaved" feminism and then the retreat towards spaces that could not be politicized by those who had been emancipated in the public space. This visit to those years is not only a way of narrating the history of southern feminism, it is also an opportunity to revisit a process that illuminates current debates about the autonomy and practices of movements within the framework of southern democracies.
\end{abstract}

Keywords: Feminism, Left Wing, Uruguay, The 80's, Democracy

\section{Introducción}

Uruguay contó a principios de siglo con un importante movimiento de mujeres y feminista que incluyó tanto a quienes se reivindicaron como "feministas" como a quienes no asumieron esta denominación pero

\footnotetext{
1 Doctora en Ciencias Sociales por la Universidad General Sarmiento y el Instituto de Desarrollo Económico y Social (UNGS-IDES). Investigadora del Instituto de Ciencia Política, Facultad de Ciencias Sociales, Universidad de la República. Correo institucional: analaura.degiorgi@cienciassociales.edu.uy. Montevideo, Uruguay.
} 
desarrollaron iniciativas para alterar el lugar subordinado de la mujer. Anarquistas, socialistas, batllistas, mujeres sindicalizadas, se organizaron de diversas formas, denunciaron la desigualdad y buscaron desde diversas estrategias impugnar la desigual condición de la mujer ${ }^{2}$. La temprana ley de divorcio y el sufragio femenino en el país son algunos de los resultados concretos de aquel protagonismo de las mujeres. Sin embargo, luego de los años cuarenta, en donde el movimiento antifascista implicó nuevamente la movilización de las mujeres ${ }^{3}$, se ingresó en una etapa de desmovilización, una "siesta" (JOHNSON, 2000), que se interrumpió recién luego de la experiencia de la dictadura.

La emergencia del feminismo luego de la dictadura, se dio en el marco de un amplio movimiento de mujeres que integraba el llamado "bloque opositor" y en el contexto de la transición y la recomposición democrática. Quienes inauguraron el feminismo en esta época lo hicieron en un contexto particular en el que la centralidad de la democracia, los espacios de cooperación y la lógica concertacionista delinearon los límites para la intervención política. En este contexto emergió el feminismo y su principal vertiente, el feminismo de izquierda, que se hizo presente en la escena pública al ser protagonista de la movilización más numerosa de mujeres en 1984 y de las instancias de concertación que antecedieron al primer gobierno democrático posdictadura.

Las distintas iniciativas de este novel feminismo intervinieron en un momento específico de amplias expectativas democráticas, incorporaron en su prédica algunas claves discursivas de la época asociadas al concertacionismo y desplegaron una práctica en espacios compartidos, la cual fue fundante de un feminismo cooperador. La centralidad de la democracia y de la política como cooperación interpeló al feminismo que realizó aportes específicos a la idea de "nueva política". Esto sucedió en un contexto de amplias expectativas y de apuesta por superar lógicas adversativas. Sin embargo, hacia fines de la década el feminismo no pudo constatar las promesas de la democracia y la desilusión creció de forma constante.

\footnotetext{
2 Ver Cuadro (2018), Johnson (2000).

3 Ver De Giorgi (2016) y Leibner (2004).
} 
En pocos años el cansancio y el enojo condujeron a discutir y reflexionar sobre la pertinencia de una estrategia de masas y fundamentalmente sobre el feminismo en los partidos. Autonomía, autoconciencia, encuentro, fueron términos que comenzaron a ocupar mayor protagonismo a fines de la década. En el contexto de otras expectativas, de cansancio y agobio, el feminismo realizó una importante autocrítica respecto a su praxis, a la herencia de las prácticas políticas tradicionales de la izquierda y buscó repensarse desde otros espacios de intervención.

Este artículo tiene por objetivo principal reconstruir la historia del feminismo de izquierda en el Uruguay de los ochenta, focalizando el análisis en la tensión que atravesó a estas iniciativas respecto a las estrategias y sus prácticas políticas. Este texto describe y analiza el campo de posibilidades delineado por las altas expectativas con la política democrática que incentivaron un feminismo "bien comportado" y el pasaje hacia algunas irreverencias por parte de aquellas que resistieron en los espacios partidarios o ingresaron a la institucionalidad estatal, y el repliegue hacia espacios que no lograban ser fácilmente politizados por parte de quienes se habian emancipado en el espacio público. Esta revisita a aquellos años no es sólo un modo de narrar la historia del feminismo del sur, también es una oportunidad para revisitar un proceso que ilumina debates actuales sobre la autonomía y las prácticas de los movimientos en el marco de las democracias del sur.

Este artículo ofrece los resultados de una investigación de corte histórico que construyó un importante archivo documental. En este texto se recurre principalmente a fuentes primarias, especialmente a intervenciones en la prensa feminista, como las revistas feministas Cotidiano y La Cacerola, y el suplemento La República de las Mujeres, un emprendimiento editorial en el que confluyeron varias feministas de izquierda y que adquirió un rol protagónico hacia finales de la década. También se referencian los informes de los espacios orgánicos a las élites dirigentes, los escritos de feministas en las publicaciones oficiales de los partidos y los textos elaborados desde una adscripción partidaria. 


\section{"Montevideo era una fiesta" y nueva política}

La década del ochenta en Uruguay se inicia con lo que se considera un hito fundamental de la transición: el rechazo de la ciudadanía a la propuesta realizada por la cúpula militar de permanencia en el poder ${ }^{4}$. A partir de este plebiscito se procesó una paulatina apertura del espacio público, retornaron los partidos políticos y se sumaron nuevos actores. Retornaron los partidos políticos, que en comparación con otros países en la región tuvieron un alto grado de sobrevivencia, se recuperó el movimiento sindical y el movimiento estudiantil. Otros espacios, menos estructurados y más novedosos, también conformaron el mapa de la participación ciudadana de los primeros años de la década, como fue el caso de las primeras organizaciones de DDHH y de la participación a nivel barrial.

En las instancias de participación barrial de los primeros años de la década, las mujeres juntaban alimentos y ropa para los presos políticos, cocinaban en las ollas populares y se reunian en los hogares o en las parroquias para circular información. Un utensilio característico del espacio doméstico, la cacerola, se transformó en un instrumento de protesta en el espacio público y, así, en agosto de 1983 se comenzaron a golpear las cacerolas desde los hogares contra la dictadura. Si bien su intervención en el espacio público se tradujo en actividades ancladas en los tradicionales roles de género, este tipo de participación también fue transformadora porque permitió a las mujeres percibirse como capaces de incidir en la vida cotidiana, resolviendo problemas concretos (JOHNSON, 2000, p. 76).

Como señala Feliú (2009, p. 72), a diferencia de lo sucedido en Europa y Estados Unidos, en los países del Cono Sur, en el contexto de las transiciones, el término "movimiento de mujeres" fue el privilegiado para congregar a mujeres que, de una u otra forma, entendian que ellas ocupaban un lugar subordinado respecto a los hombres. La emergencia de las organizaciones feministas se realizó en ese contexto de un amplio movimiento de mujeres que legitimaba al feminismo (Costa, 1988), le otorgaba un respaldo

\footnotetext{
${ }^{4}$ Este proyecto proponía la elección de la presidencia entre candidatos del Partido Colorado y el Partido Nacional (y la exclusión implícita del Frente Amplio), un tribunal militar con potestades de juzgar a los legisladores e intervenir en desacuerdos entre el Poder Ejecutivo y el Poder Legislativo, la sustitución del sistema de representación proporcional por el principio mayoritario en las Cámaras, un Consejo de Seguridad Nacional controlado por militares y la eliminación de la autonomía departamental y universitaria.
} 
a la vez que establecía límites para el despliegue de ciertas ideas. A partir de 1984 se hicieron visibles los primeros grupos y figuras feministas y hacia 1986 se terminó de conformar el mapa del feminismo de esta década.

En el caso uruguayo, gran parte de las iniciativas feministas estuvieron asociadas al campo de la izquierda. Las organizaciones sociales feminista estuvieron ampliamente ligadas a la izquierda, por estar lideradas por dobles militantes o figuras muy cercanas a la izquierda y por desarrollar una interpretación de la subordinación de la mujer en clave marxista. Además el feminismo de izquierda contó con un importante número de comisiones de mujeres en los partidos políticos, que aunque impulsaron grupos que no utilizaban el término "feminismo", estuvieron lideradas por feministas con participación en las organizaciones sociales ${ }^{5}$.

En las organizaciones sociales feministas no se desplegó una prédica en oposición a los partidos o de la izquierda. Las organizaciones sociales elaboraron un discurso feminista dentro del campo de las ideas de la izquierda y no contestaron de forma radical las prácticas politicas tradicionales. Las distintas actividades dentro de los espacios partidarios -encuentros, talleres, charlas- contaron de forma recurrente con feministas de las organizaciones sociales. Desde los espacios partidarios tampoco se concibió a las organizaciones sociales feministas o a quienes allí participaban como alejadas de la preocupación por transformaciones estructurales, como espacios despolitizados, que ubicaban la denuncia de la opresión patriarcal por encima de la de clase, ni consideraron a las integrantes de las organizaciones sociales como alejadas de la politica. Esta configuración tuvo importantes consecuencias en la praxis del feminismo.

Las iniciativas feministas emergieron en un contexto particular de altas expectativas democráticas. El año 1984, año de las primeras elecciones generales y preparación para la inauguración del primer gobierno democrático posdictadura fue especialmente significativo para delimitar el contexto del

\footnotetext{
5 Las principales organizaciones que integran al feminismo de izquierda en el Uruguay de los ochenta son: el Grupo de Estudios de la Condición de la Mujer (GRECMU); Cotidiano Mujer; la Comisión de Mujeres Uruguayas (CMU); la Comisión de la Mujer del Partido Comunista (PCU); la Comisión de la Mujer del Partido por la Victoria del Pueblo (PVP); la Comisión de Mujeres del Partido Socialista (PS); la Comisión de Mujeres del Frente Amplio (FA). La única organización social feminista no vinculada al campo de la izquierda fue el Consejo Nacional de la Mujer (CONAMU). Ninguna de sus integrantes pertenecía a la izquierda ni eran votantes, y su estrategia de intervención no se articulaba con ninguno de los grupos de mujeres en el territorio que de una u otra forma tenían vínculo con la izquierda.
} 
feminismo. Las elecciones nacionales fueron vistas como una oportunidad para rediscutir la participación política de las mujeres y realizar propuestas programáticas. El rearmado de las estructuras partidarias, el retorno de las elecciones y la vuelta a la "normalidad" fueron recibidos con alegría y amplias expectativas; en este clima, el espacio político partidario fue concebido como un lugar donde estar y construir6.

Sin dudas que esto sucedía en los ámbitos más vinculados a las estructuras partidarias, pero también en aquellas noveles organizaciones sociales que, aun fundándose como autónomas, participaron de instancias de discusión y diseño de propuestas en conjunto con los partidos o brindaron apoyo específico. En esta etapa no se consideró a las estructuras partidarias y los mecanismos eleccionarios como instancias patriarcales, respecto a lo que nada se podía hacer, ni se pensó que la democracia era una "farsa", como sucedía en gran parte de los planteos del feminismo de la segunda ola, fundamentalmente en Estados Unidos. Muy por el contrario: la democracia fue considerada el régimen ideal que había que recuperar y fortalecer. El relato de los primeros años posdictadura se mantuvo en ese registro de recordar la capital "toda embanderada", en donde primaba "la euforia", "la alegría" y cuando "Montevideo era una fiesta"

En el año 1984, además de las elecciones generales, otro proceso recentró las energías de las mujeres movilizadas hacia la política institucional. Esto sucedió en el ámbito de la Concertación Nacional Programática (CONAPRO), un espacio en el que convergieron partidos políticos, organizaciones sociales y empresariales que de forma concertada debía elaborar propuestas programáticas para ser puestas en práctica el 1 de marzo de 1985. En este espacio se conformó El Grupo de la Condición de la Mujer que trabajó intensamente y logró elaborar cinco documentos de propuestas. Este fue un ámbito de trabajo político para elaborar recomendaciones de políticas públicas, no fue un espacio de discusión profunda sobre ciertas temáticas cardinales para el feminismo, pero sí un ámbito para, por primera

\footnotetext{
${ }^{6}$ Ana Veiga relata un fenómeno parecido con relación a las revistas Brasil Mulher y Nós Mulheres, que en los años electorales realizaron un amplio respaldo a los mecanismos democráticos, a la importancia de votar y de contar con candidatas (Veiga, 2009, p. 134).

7 Intervención de Graciela Sapriza en el Seminario "Encuentro interdisciplinar: A 30 años de 1985. Los debates académicos en torno a la democracia de los ochentas", Facultad de Ciencias Sociales, Montevideo, 3 de diciembre de 2015.
} 
vez, someter ciertas temáticas a debate. La experiencia de la CONAPRO fue fundacional de una práctica política del encuentro.

Un encuentro en el que el feminismo depositaba expectativas para construir una nueva política y que se articulaba con el clima emocional de aquellos años, de lógica concertacionista y de abandono de la política adversativa (LESGART, 2003). El discurso hegemónico de la época, que hizo hincapié en la tradición democrática, en un mítico pasado participativo y en una cultura política democrática, también interpeló al discurso feminista. La democracia fue un término central para el feminismo de izquierda de aquellos años en su versión mínima, procedimental, y en su versión sustantiva. Lo primero llevó a reclamar mayor participación de las mujeres en los espacios de la politica tradicional. De forma recurrente aparecian las referencias a un "nuevo país”, un "nuevo Uruguay" y una "nueva política” que no sería posible "sin la participación de la mujer" ("No habrá un nuevo Uruguay sin la plena participación de la mujer", Cotidiano, abril de 1986, Año 1, № 5, portada).

Un concepto de democracia sustantiva disputaba la noción de democracia como procedimiento, definida por los espacios partidarios y la competencia electoral. Esa democracia sustantiva dependía de otra política, que trascendiera los espacios partidarios, en los que se desarrollaba una politica de y para hombres que parecía ser objetiva y racional, pero que no lo era; las mujeres podian construir esa otra politica más humana, como proponian desde La Cacerola:

Juntas nos dimos cuenta que hacer politica no es solo hacer politica partidaria. Estos movimientos [los de mujeres] que no excluyen la militancia política y la sindical son otras formas de hacer política. Nos permiten expresar y afirmar nuestras propias propuestas como mujeres y crean una base real frente a la que los partidos políticos podrian comprometerse. (...) Nuestras propuestas incluyen valores realmente humanos en los que la calidad de vida y la igualdad en las relaciones predominen sobre la competencia despiadada, el autoritarismo y la destrucción en la que aparecen empeñados los racionales hombres que manejaron y manejan la política. Por ello el espacio que hemos ganado las mujeres debe ser mantenido y fortalecido cuando conquistamos la democracia, para que esta no sea solo formal sino real. (LA CACEROLA, Año 1, $\mathrm{N}^{\circ}$ 3, noviembre 1984, portada),

\section{Ampliar la base y crecer}

El contexto de recuperación de los canales de participación para la emergencia de estos discursos de "otra política", estableció sus límites. Al 
mismo tiempo que reclamaban otra política por fuera de aquella entendida como tradicional y jerárquica, de algún modo también contribuían a ella, demandando espacios o reproduciendo algunas de sus lógicas. Los esfuerzos por plantear prácticas y asuntos por fuera del discurso hegemónico convivieron con el interés en no abandonar los espacios tradicionales, de apostar también al "entrismo feminsita". La subrepresentación a las mujeres en los espacios partidarios fue un fenómeno que interpeló día a día a las feministas, fundamentalmente a las dobles militantes que para el caso uruguayo eran un número significativo.

Ilustración 1 - Circulación de las dobles militantes

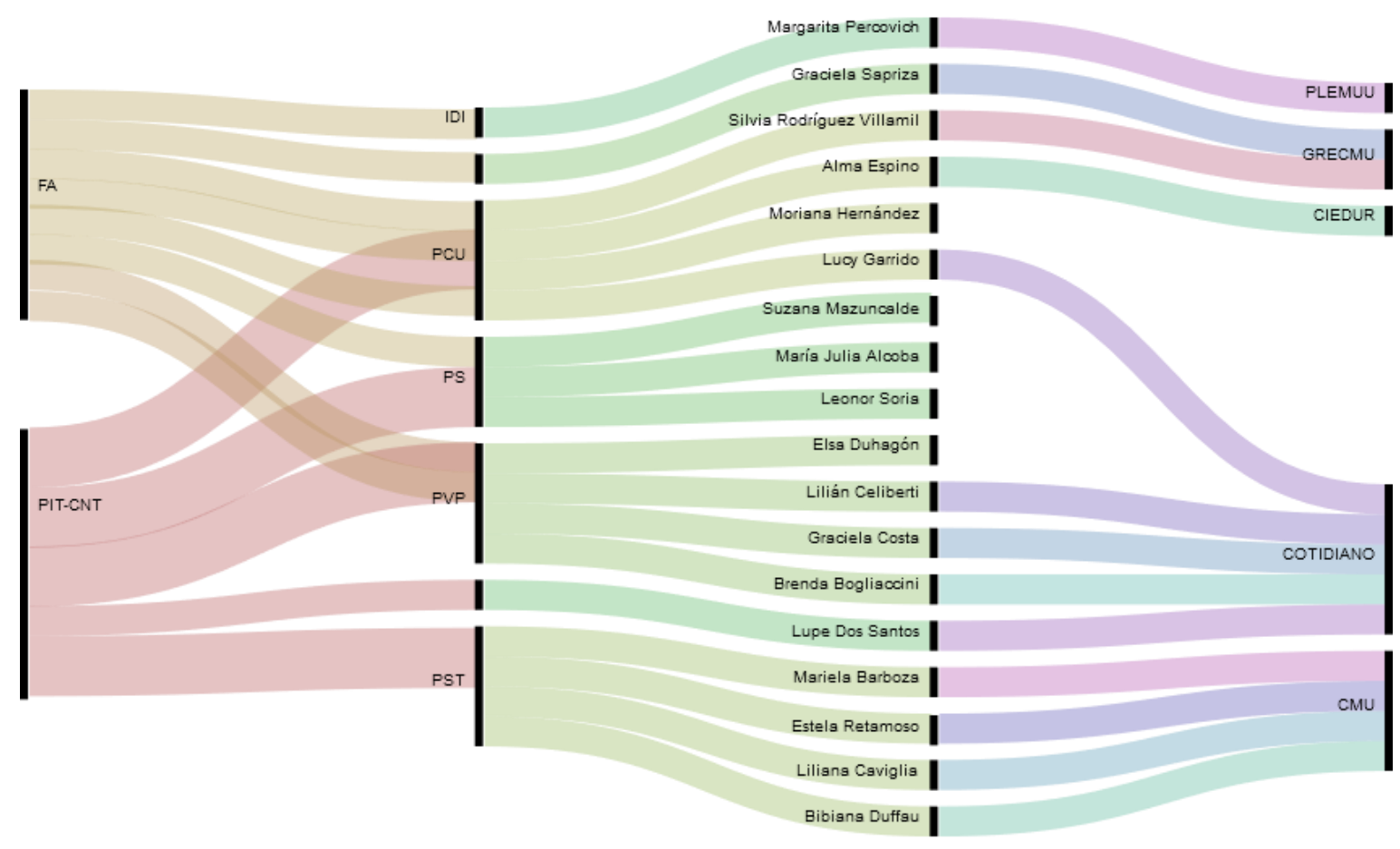

Fuente: Elaboración propia a partir de fuentes orales

En el esquema se pueden apreciar los vínculos entre distintas organizaciones y la circulación de las dobles militantes. Aunque la discusión sobre la autonomía se planteó desde los inicios del feminismo latinoamericano (RESTREPO, 2016, p. 442), la condición de dobles militantes en la primera etapa no fue visualizada como problemática por parte de las feministas; en todo caso esta era una preocupación que emergía de las organizaciones partidarias y de los compañeros que veían en el feminismo una amenaza a la cuestión principal de la lucha de clases. 
En los primeros años de la emergencia feminista en Uruguay, no se produjo una escisión entre "feministas" y "politicas". No surgieron autonominaciones de "feministas puras", “independientes" o “autónomas", que denunciaran los espacios partidarios como patriarcales y convocaran a abandonarlos. En este sentido no existieron grupos que reivindicaran como "independientes" y apostaran a un feminismo por fuera de los partidos políticos ${ }^{8}$. No se sospechó de las feministas en los partidos como enviadas para llevar un mensaje, ni se las consideró sin poder de agencia.

La emergencia de grupos feministas dentro de las organizaciones partidarias no se debió a que los partidos y sus elites dirigentes se hubiesen vuelto receptivos al feminismo, sino que fue el resultado de una decisión y un esfuerzo realizado por ellas. En tal sentido, aquí se propone leer este proceso no como producto de una estrategia de cooptación e instrumentalización que las organizaciones partidarias desarrollaron, como se lo suele describir en los relatos de aquellas que transitaron por los espacios partidarios y luego los rechazaron, así como en varias investigaciones que estudian el desarrollo del feminismo en la región ${ }^{9}$.

El feminismo cooperador, la articulación de las ideas feministas con un proyecto político de cambio estructural, la doble militancia de muchas de sus protagonistas y la cercanía de las independientes con el Frente Amplio fueron elementos centrales para configurar una praxis feminista que en casi todo el período estuvo cercana a los imaginarios y prácticas de la izquierda uruguaya. A pesar de algunas acusaciones de la época que interrogaban por

\footnotetext{
8 Las autodenominaciones de "autónomas" con la consecuente señalización de las otras como "institucionalizadas" es parte de un debate que continúa hasta la actualidad y que tuvo su expresión inaugural en los noventa. El VI Encuentro realizado en El Salvador en 1993 y luego el VII en Chile en 1996 fueron instancias claves de esta discusión en la que se debatió en torno a la autonomía respecto al Estado y los organismos internacionales, aunque también el grupo autónomo en Bolivia Mujeres Creando nacido a principios de los noventa fue especialmente crítico con los partidos. La literatura sobre este debate es extremadamente vasta; sólo a modo de ejemplo, se pueden señalar algunos textos imprescindibles: Álvarez (1998); Falquet (2014); Espinosa 2007; De Souza (2018); Restrepo (2016); Rivera (2009); Toro (2007). Las voces de algunas de las protagonistas de la discusión en el VII Encuentro se encuentran en Olea (Comp.) (1998).

9 En varios textos elaborados por quienes se autodenominan "feministas autónomas" en otros países aparece esta idea sobre las feministas provenientes de los partidos como mujeres instrumentalizadas por las direcciones partidarias (FISCHER, 2005, p. 61). Este tipo de apreciaciones algunas veces también han emergido de las propias feministas. En el testimonio de una de las protagonistas del primer Encuentro Latinoamericano se puede tomar conocimiento de ese fenómeno de alguien que había transitado por los partidos y luego rechazaría esos espacios (Suaza, 2009, p. 49). En el trabajo sobre las trayectorias feministas realizado por Joana Pedro, un testimonio de una feminista militante del Partido Comunista Brasilero señala que el partido la enviaba a "reclutar" (PEDRO, 2010, p. 126). Laura Restrepo realiza una presentación de los Encuentros Feministas Latinoamericanos como un espacio en el que la autoconciencia se contraponía al "adoctrinamiento en los partidos políticos" (2016, p. 227).
} 
los motivos de reunirse "solas", las feministas, en distintos espacios, enunciaron su rechazo al gueto y apostaron a una politica "amplia".

Para aquellas que participaban en las izquierdas, la doble militancia no sólo no se consideraba un problema sino que representaba una ventaja, porque desde los partidos, como se decía en el lenguaje de la época, se podia "ampliar la base" y llegar a aquellas mujeres aún no feministas, las doblemente explotadas en términos de clase y género, las mujeres de los sectores populares (NAVARRO, 1982). A las feministas, el legado leninistaguevarista las hacía considerarse dentro de los partidos como la vanguardia de un movimiento de mujeres (STERENBACH ET AL., 1994, p. 261). Claramente la centralidad que ocupaba el "llegar a las otras", tomaba distancia de la práctica de la autoconciencia, pero permitía discutir sobre aquellas mujeres no reconocidas feministas, fundamentalmente de los sectores populares que en América Latina eran un contingente muy importante.

Durante los primeros años de la recomposición democrática el clima político de altas expectativas no instó a realizar grandes impugnaciones. Las nuevas formas de hacer politica debían convivir armoniosamente con aquellas viejas $\mathrm{y}$, además, también existían expectativas sobre las posibles transformaciones de estas últimas. La izquierda partidaria no era la misma o se pensaba que ya no debía serlo en un contexto de discusión sobre la militancia y las prácticas políticas. Un clima de revisión de las exigencias y el espíritu de sacrificio, junto a una demanda de mayor apertura, permeaban las discusiones de distintos espacios que comenzaban a ser señalados como rígidos y sofocantes.

GRECMU y Cotidiano, las dos organizaciones sociales feministas protagónicas, estaban integradas sólo por mujeres y tenían un discurso que planteaba la necesidad de una nueva politica o de otras formas de hacer política, sin rechazar los espacios de la politica tradicional. En La Cacerola y Cotidiano se publicaron de forma constante artículos referidos a las iniciativas en materia legislativa orientados a atender distintas situaciones de desigualdad, a las discusiones en torno a la participación politica de la mujer en sindicatos y partidos, a los desempeños y trayectorias políticas de las representantes. 
GRECMU fue, además, un ámbito de reunión y circulación de mujeres provenientes de los espacios políticos y organizó varios seminarios, como Participación Política de la Mujer en el Cono Sur en 1986 y Mujeres y Poder en los márgenes de la Democracia Uruguaya en 1990. Cotidiano también prestó atención a la izquierda partidaria y fundamentalmente a la sindical, respecto a la cual se difundieron los Encuentros de Mujeres Trabajadoras, los distintos espacios de reunión de mujeres en los sindicatos y las agendas reivindicativas en el ámbito sindical.

En los espacios partidarios las feministas señalaron las dificultades que alli existian para la participación de las mujeres, pero no instaron a abandonarlos. Las feministas justamente podrian revertir esa configuración. Silvia Rodríguez Villamil, en su columna de La Hora, señaló que era necesaria otra política, anclada en prácticas "menos masculinas y más humanas", menos jerárquica y formalista, "más práctica, con mayor aporte de lo personal y lo afectivo, de lo cotidiano" (LA HORA, domingo 6 de septiembre de 1987, p. $17)$.

Las integrantes del PST destacaron explícitamente el carácter patriarcal de los partidos y los privilegios usufructuados por los hombres, a la vez que conformaron una organización de mujeres como la CMU ante "el atraso de la conciencia de los hombres", al mismo tiempo que convocaban a permanecer en las estructuras partidarias. A pesar de que ningún partido podía ser considerado ajeno a la ideología machista, no se podía renunciar a estas organizaciones ya que no considerar estos espacios significaba "perder una batalla antes de comenzar" (BARBOZA ET AL., 1985, p. 34).

En tonos distintos se tomó distancia de las posturas exclusivistas respecto a los partidos y a los compañeros, fundamentalmente de aquellas asociadas al feminismo radical. Se pronunciaron por un feminismo distinto de aquel "de la mujer contra el hombre" porque se debian "buscar vías de diálogo, discusión y acción conjunta con los compañeros" (Silvia Rodríguez Villamil, Estudios, $\left.N^{\circ} 100,1987\right)$. La apuesta al diálogo implicó el despliegue de un discurso no combativo de un "feminismo menos estridente". El lenguaje fue parte de una práctica también menos estridente. Tanto desde las organizaciones sociales como partidarias se apostó a una praxis similar a las 
prácticas tradicionales, con el objetivo de llegar a un número mayor de mujeres.

Las organizaciones sociales integradas sólo por mujeres respaldaron la estrategia feminista para desarrollar en los espacios "mixtos" y cumplieron un rol fundamental como divulgadoras de las nuevas ideas a través de sus emprendimientos editoriales, desde donde se explicó qué era el feminismo, cuál era su historia y su agenda de lucha. Aun lideradas por feministas con alto nivel educativo, La Cacerola y Cotidiano no fueron revistas teóricas del feminismo, aunque sus sedes sí fueron espacios de estudio y formación para aquellas ya feministas. Así como espacios de encuentro y circulación fueron instancias fundamentales de formación para quienes luego salieron "al terreno" a convocar a otras mujeres, estrategia que se realizó principalmente desde los espacios partidarios.

Ampliar la base - del feminismo y de la izquierda-fue considerado una prioridad. La demanda por mejores condiciones de participación para las mujeres fue justificada a partir de que ellas serian la principal herramienta para llegar a otras, dado que podían, mejor que nadie, llegar a los hogares, a la casa de cada una y ampliar la base (Nosotras, Año 1, $\mathrm{n}^{\circ} 1,1987$ ). La agenda feminista debía ser llevada a los barrios, a las mujeres populares o "de base". No alcanzaba con elaborar propuestas programáticas o proyectos de ley, era necesario "salir al terreno" y llegar a quienes aún no eran feministas y se encontraban en el mismo terreno de la militancia de izquierda, como explica Cristina, una feminista de un grupo de mujeres del PVP:

\begin{abstract}
Sabíamos que las más perjudicadas de las mujeres son las más pobres. No, no, no tenía sentido que fuéramos a hacer trabajo feminista al Club de Golf, a ella no les interesaria, no sé. Nosotras estábamos para un tema donde tenía prioridades. El feminismo estaba de mano de la izquierda para cambiar la sociedad, las injusticias sociales. No es que estuviéramos atrás de las pobres, pero sí había más vínculos con las mujeres de sectores populares, porque era donde se armaban comisiones de mujeres, nunca vimos una comisión de mujeres de Carrasco, eran comisiones de gente que se organizaba por otros temas y luego salía la comisión de mujeres, eran cosas que surgían de la izquierda.
\end{abstract}

Qué decir y cómo decirlo fue una preocupación constante. Recurrir a un lenguaje llano despojado de referencias autorales y abstracciones teóricas se consideró un requisito para quienes no habían realizado un proceso de reflexión feminista, al menos no en los términos en que sí lo habían hecho las 
referentes, es decir, a través de textos y nuevos conceptos teóricos. El "ejercicio de traducción" implicaba adaptar a la realidad concreta de las mujeres la idea de opresión o mandatos de género.

Desde las organizaciones partidarias esta estrategia parece haber reeditado una vieja práctica de la izquierda según la cual el partido y sus élites fungian como una vanguardia, en términos culturales, para quienes se acercaban a ese espacio o se formaban políticamente allí. En el caso del acercamiento a las ideas feministas, se concibió una estrategia similar que permitiera llegar a aquellas que aún no habian incorporado estas nuevas ideas. Esta tarea no era sencilla, porque el feminismo buscaba tomar distancia de las prácticas anteriores hacia las mujeres de las "ramas femeninas" que no cuestionaban los roles de género vigentes, pero a la vez, con un discurso marcadamente feminista, no podía llegar a las mujeres de sectores populares.

La Comisión de Mujeres del FA elaboró una sugerente calificación: a) la mujer que participa activamente; b) la mujer que no participa porque no puede; y c) la mujer que no participa pero no es consciente. Para cada uno de los grupos se pensaron distintas estrategias de concientización. Las primeras serian las que mejor recibirian las ideas feministas, pero el lenguaje debía ser cuidadoso para que finalmente pudieran admitir ser el "colchón" de todos los problemas familiares. Las segundas también serian un público relativamente accesible si se le ofrecían condiciones para que pudieran lograr efectivamente la participación. Por último, el tercer grupo implicaba los mayores desafios, dado el gran trabajo de concientización que se debía realizar para aquellas que no visualizaban la opresión hacia la mujer (Planteo político para la Mujer, Informe de la Sub Comisión de Programa del FA, Comisión de Mujeres del FA).

La movilización política fue así entendida como el instrumento imprescindible para el devenir feminista, para el progreso de la conciencia, que debía tramitarse en lo público. Toda movilización política debía ser considerada una oportunidad emancipatoria, aun cuando se anclara en un repertorio de prácticas que se buscaban revisar:

La lucha contra la carestía, en las ollas populares, etc., no son luchas feministas, no cuestionan la opresión de las mujeres como sexo. Sin embargo, ninguna política de masas para las mujeres hoy puede desconocer el papel politizador y unificador que estas luchas pueden asumir incluso en las camadas más atrasadas de mujeres (BARBOZA ET AL., 1985, p. 38). 
Si bien desde la Comisión de Mujeres del Frente Amplio se realizaron una serie de talleres, liderados muchas veces por las "académicas feministas", la estrategia principal fue la intervención en pequeñas reuniones en los barrios bajo las orientaciones definidas en las "Charlas Tipo". Estas fueron pensadas de modo que pudieran ser impulsadas por las distintas referentes a partir de una narración general que dinamizara las reuniones. Los puntos imprescindibles debían ser los siguientes: 1) la justificación del abordaje de la problemática de la mujer en un Comité del FA; 2) el proceso de toma de conciencia del lugar subordinado de la mujer a partir de la descripción de diversos fenómenos (doble jornada laboral, desigualdad salarial y resistencia a la dictadura), que daban cuenta de experiencias frustrantes que llevaban a la toma de conciencia; 3) los datos sobre los bajos niveles de participación política y las condiciones que generaban dicho fenómeno, y 4) las propuestas del FA para revertir la situación ${ }^{10}$.

Estas charlas tenían una lógica de transmitir ciertos conocimientos de las expertas a otras que no lo eran, en un estilo mucho más de generación de conciencia que de concienciación en los términos del feminismo. En estas charlas, quienes asistian a ellas no intervenían en igualdad de condiciones respecto a las feministas que las lideraban. Sin embargo, tampoco eran los espacios formalizados de la izquierda comunista como aquellos de las Escuelas Elementales o Vespertinas, en los que se leían textos teóricos, se incorporaban conceptos y se rendian pruebas.

Los distintos talleres y charlas buscaban llegar a aquellas no feministas desde dinámicas orientadas a interpelar a las participantes desde sus vivencias cotidianas. La disposición de las sillas, en círculo, daba cuenta de otro tipo de intercambio, algo especialmente señalado por sus participantes en las intervenciones y que evidencia lo novedoso que era en relación con las prácticas políticas tradicionales (Taller de trabajo con mujeres trabajadores, $\mathrm{s} / \mathrm{f}$. La dinámica de estos talleres posiblemente se inspirara en los talleres de la educación popular que fueron característicos de la praxis feminista

\footnotetext{
10 Este tipo de intervención orientada a aumentar la concientización de las mujeres fue una práctica que se continuó de forma constante y que se fortaleció luego en 1990 con la implementación de planes para la formación de mujeres en los barrios de Montevideo y de las edilas en todo el país.
} 
latinoamericana y que tuvo a Moema Viezzer como una de sus principales impulsoras, referenciada además en algunos materiales de GRECMU. ${ }^{11}$

\section{Esta democracia que nos hace cancelar nuestra rebeldia}

La intervención feminista y su apuesta por aumentar la conciencia sobre la opresión de género se focalizó en la difusión de ideas, agendas y llegar a otras a través de talleres para mujeres o cursos de capacitación. Tanto Cotidiano como GRECMU fungieron como espacios de formación constante para las propias feministas, que en la preparación de los materiales, de la prensa y de la elaboración de artículos realizaban un continuo proceso de formación y reflexión, pero no hubo ni en las comisiones de mujeres conformadas en los partidos ni en las organizaciones sociales una dinámica de pequeño grupo ni de un trabajo de concienciación.

En términos generales - y coincidiendo con una pauta observada en los países vecinos -, en el Uruguay de los ochenta los grupos de autoconciencia no fueron el modo característico de la intervención feminista. Posiblemente estas iniciativas no se desarrollaron por ser consideradas poco “politicas", en un contexto en el que la gran politica retornaba a escena, o por estar más asociadas a las prácticas del feminismo radical del que se buscaba tomar distancia ${ }^{12}$. Todo aquello que fuera hacia un registro más de lo personal ocupaba un lugar subordinado aun entre aquellas que justamente como principal consigna tenían "lo personal es político". La reapropiación del mundo de las mujeres era una tarea más que compleja, sobre todo porque de aquel mundo era justamente de donde se había querido huir y abordar lo privadoíntimo era considerado, de algún modo, despolitizador.

El tránsito hacia otro lenguaje y otras prácticas no fue sencillo, sobre todo en los espacios partidarios en los que pervivian las lógicas de intervención masculinas. Aquellas que se incorporaban a estos espacios reivindicando su participación como mujeres y buscando contestar algunas prácticas se encontraban con algunos obstáculos. Aquellos compañeros que alentaban la

\footnotetext{
11 Como señala Moyano (2016, p. 14) el "taller" como espacio de discusión y reflexión había sido una práctica desarrollada en los sesenta en el campo de las ciencias sociales en Chile y había sentado un precedente importante para la investigación-acción.

$12 \mathrm{El}$ análisis que realiza Albertina Costa de Oliveira (1988), para el grupo de feministas conformado en San Pablo a principios de los setenta, da cuenta de cómo el contexto de la dictadura, en el que toda reunión estaba prohibida, posibilitó la reunión en un grupo chico, sin recibir las críticas de los compañeros de militancia.
} 
participación de las mujeres les recordaban que debían esforzarse y trabajar mucho para poder ser escuchadas, como encomendó José D'Elía a sus compañeras que debían "estudiar sus problemas específicos para asesorar a la Central [PIT-CNT] y discutir con solvencia" (La República de las Mujeres, 1 de abril, 1990, p. 3).

Entonces quienes ingresaban a los espacios partidarios o sindicales, aun teniendo una preocupación por su condición de mujer, debieron "aprender a hablar y moverse entre ellos" y sentirse capaces de "ganarle la cabeza a los compañeros" (La República de las Mujeres, 29 de octubre, 1988, p. 7). Para las recién llegadas no fue sencillo contestar las prácticas tradicionales, pero tampoco lo fue para quienes venían de una trayectoria más larga, porque también se habian socializado en aquellas lógicas. En este sentido, parece arriesgado dar cuenta de una "cultura política feminista" idea que sostiene Cuadro (2018) para el feminismo de principios de siglo- en el marco de la naturalización de las prácticas de la cultura de la izquierda.

Las prácticas políticas heredadas dificilmente podian ser objeto de contestación, además, porque eran las mismas prácticas que a ellas, mujeres, les habian permitido realizar ciertas transgresiones de género durante los sesenta. Pararse arriba de un banco en un centro estudiantil y realizar un discurso, subirse al estrado en un acto partidario o hablar en una asamblea había sido y continuaba siendo para varias un ritual emancipatorio. Habían realizado un esfuerzo enorme por aprender a hacer discursos, aprender a hablar "como ellos", ajustarse a los criterios de discusión, elaborar documentos, citar referentes teóricos y "salir de la cocina". Desandar ese trayecto no fue una tarea para nada sencilla.

El esfuerzo realizado en tiempo, horas de estudio, reflexión y elaboración de un argumento no sólo fue un resultado casi natural de una práctica adquirida sino también una necesidad estratégica para poder ser escuchadas. Resultó algo imprescindible saber discutir, argumentar, contestar las críticas desde una postura sólida, coherente, basada en datos objetivos y argumentos teóricos. $\mathrm{Y}$ esto fue especialmente necesario para quienes participaban en los espacios denominados "mixtos", es decir, con compañeros varones, donde esta estrategia resultaba imprescindible para ser parte de la discusión en los términos ya definidos de la política tradicional. 
En este sentido, el feminismo había que militarlo con la misma dedicación con la que se había militado por la revolución. Con esa idea de las "feministas fuertes", habilitaron con su práctica una paradoja: aquellas que querian reconciliar la política con la vida, hacer de lo personal algo político, vivir, expresarse más libremente, sentir, compartir, acompañarse, reconocerse en la subordinación y la vulnerabilidad, todo lo que no habían podido realizar en espacios masculinizados, con su dedicación dificultaban aquel objetivo. En 1988 Kirai de León planteó algunos de estos temas, interrogando sobre los modos de "pasar de conocer y reconocer la subordinación de las mujeres en general a la de una misma", en una nota cuyo título es más que sugerente: "De conciencia abstracta a conciencia crítica":

[...] el conocimiento formal o informal -la transmisión de la investigación sobre la mujer o la capacitación que de ella se deriva- no asegura por sí solo la toma de conciencia de nuestra subordinación. A la conciencia crítica tal vez sólo se acceda "escudriñando para adentro", "compartiendo las experiencias de todas". Romper el monopolio del conocimiento, valorar el aporte de los sentimientos y la emotividad, de la recreación de un lenguaje de mujeres en espacios de mujeres (LA CACEROLA, Año 5, $\mathrm{N}^{\circ}$ Especial, marzo 1988, p. 3).

Esta reflexión se procesó en el contexto de la discusión sobre las estrategias del movimiento feminista y los espacios de participación. El avance de los años durante la década en estudio estuvo acompañado por un crecimiento también en la frustración con la democracia, con las expectativas de cambio y con los espacios de la política tradicional. Entonces fue cada vez más recurrente el llamado al grupo chico, a reunirse en encuentros y no en seminarios, a buscar formas de reflexión y participación que contestaran algunas prácticas políticas que las feministas también habían reproducido y que en el epílogo de la década comenzaron a repensar, aunque ya no con el impulso inicial de los primeros años de la transición.

La estrategia cooperadora, la cercanía con los compañeros y los partidos políticos, la ausencia de espacios compartidos de reflexión sobre las experiencias personales concretas no significaron, en modo alguno, una reproducción total de las prácticas de la política tradicional. Reunirse sólo entre mujeres, dentro o fuera de las organizaciones partidarias, desarrollar una prensa feminista, escribir columnas feministas en la prensa partidaria o nacional, convocar sólo a las mujeres a seminarios, congresos, cursos, talleres, utilizar un lenguaje más llano y desplegar una agenda que politizaba 
Nosotras, entre defender lo propio y avanzar a la amplitud | Ana Laura de Giorgi

asuntos antes no abordados integraron un repertorio de apuestas transgresoras. La falta de escucha, las sanciones morales, las burlas y el rechazo recibido son una muestra clara de ello.

Las latinoamericanas, señala Francesca Gargallo (2014, p. 54), nunca fueron tan visiblemente radicales como las europeas o las estadounidenses, "porque el mandato de ser dignas y decentes les era imperativo para obtener el reconocimiento de las corrientes politicas progresistas, por la representación interiorizada o porque las costumbres machistas las exponían a una violencia inmediata y brutal". Las uruguayas militaron el feminismo como militaban en la izquierda: salian al terreno, a formar a otras, a intervenir en la prensa, a movilizar y concientizar, a llevar la agenda feminista en un contexto hostil del que no retornaba casi nada bueno.

Las amplias expectativas que la democracia y la politica partidaria generaron en los primeros años de la recomposición democrática dieron lugar, al poco tiempo, a sentimientos negativos de desilusión o derrota. La democracia no había traído tantas oportunidades de participación y discusión de nuevas agendas, sino más bien la restauración de viejos liderazgos y formas de hacer política tradicional. En distintos ámbitos - no sólo en el campo del feminismo -, el término "restauración" daba cuenta de que la promesa sobre la nueva política no se había cumplido (REMEDI, 2016. p. 174). Los nuevos actores del momento discutían de forma constante cuánto era necesario “transar, negociar y adaptarse al sistema” (SEMPOL, 2014, p. 137), y a la vez eran conscientes de que resultaban fagocitados en la participación en el juego democrático. En los apuntes sobre un intercambio en aras de la conmemoración de un 8 de Marzo, posiblemente de 1987 o 1988, una de las propuestas para la proclama -que finalmente no logró apoyo - consignaba lo siguiente: "Repudio a esta democracia que nos quiere hacer tragar esta rebeldia”.

Si la democracia había incumplido promesas, los actores protagónicos de este proceso, en el caso uruguayo, sin duda habian sido los partidos politicos, incapaces de incorporar una nueva agenda o de brindar mayores oportunidades de participación política a las mujeres. La tan ansiada democracia había retornado, pero ni una mujer había ingresado al Parlamento en 1985. Para las siguientes elecciones de 1989 la preocupación continuaba 
siendo la misma por parte de las feministas que no habian podido observar ningún avance en materia de representación o discusión sustantiva.

En 1988, una nota de La Cacerola, titulada "Comisiones de mujeres. En busca de la horizontalidad", visibilizaba a las mujeres dentro de los espacios partidarios, a la vez que interrogaba sobre las dificultades de participación. Las preguntas evidencian un tono de desconfianza respecto a los partidos, que no se observa en años anteriores; además de dar cuenta de los esfuerzos realizados por las integrantes de las comisiones, expresa las sospechas sobre la "reproducción de lógicas patriarcales" (LA CACEROLA, Año $5, \mathrm{~N}^{\circ} 8$, diciembre 1988 , p. 3).

La decepción con los partidos políticos fue fundamentalmente con la izquierda, con aquel espacio al que se le habian destinado tantas energias y parecía comportarse de forma similar a los partidos "reformistas". En el contexto de esta desafección, a fines de la década comenzó a surgir un enojo específico con las estructuras y los compañeros. El nuevo hombre nuevo no era más que una utopía y el machismo, una realidad que alcanzaba a todos.

Albertina Costa señala para el caso brasileño que el feminismo "bien comportado" fue posible mientras no hubo una "patrulla ideológica" que fungió como incentivo para tomar posturas de mayor enfrentamiento por parte de las feministas (COSTA, 1988, p. 66). Algo similar parece haber sucedido en Uruguay. Aquel discurso que señalaba que sólo la izquierda podría alojar las ideas feministas y que se debía apostar al diálogo constante fue suspendido y se dio paso a la denuncia de la exclusión, las lógicas patriarcales, el machismo de los compañeros, la doble moral y los discursos oportunistas en torno a la cuestión de la mujer sin mayores transformaciones.

Una nota en 1988 de La Cacerola, titulada "El poder que nos excluye" (LA CACEROLA, Año 5, Nº julio 1988, p. 6), recopiló el repertorio de iniciativas sobre la cuestión de la mujer que no habian sido consideradas en el Parlamento. Asimismo, los prólogos escritos por Celiberti y Garrido en el texto Mi habitación, mi celda dejan entrever un estado de ánimo marcado por el enojo y la decepción. El relato fue presentado como un resultado de "la necesidad de reivindicar el derecho a la palabra, nacida del hartazgo de una politiquería que cierra las tenazas del poder sobre nuestros sufrimientos" (1990, p. 8). Una nota de Cotidiano publicada por La República de las Mujeres, 
titulada "Las feministas ¿luchamos contra los hombres?", claramente mostraba los signos del cansancio de los buenos modales:

\begin{abstract}
Juguemos limpio. Hablemos claro. Es cierto, odiamos muchas de las actitudes de los hombres (...) odiamos que se consideren los únicos capaces y autorizados para organizar el mundo y los temas importantes de la vida, mientras nos reservan la casa y los niños y desvalorizan nuestro trabajo. No nos hace ninguna gracia que vean en nosotras el cuerpo que pueden poseer o el útero que engendrará "sus hijos". (...) Por eso luchamos contra el empresario que abusa de nuestra condición de mujeres para explotarnos más, pero también contra el compañero de clase que no se moviliza por nuestras demandas laborales. Contra los que detentan el poder con mayúscula, pero también contra el tirano doméstico que nos pasa factura por el salario que trae a la casa (...) Contra los que nos impiden abortar en buenas condiciones médicas pero también contra el hombrecito que se desentiende de su hijo que ayudó a hacer. (...) Odiamos las actitudes de prepotencia y autoritarismo que los hombres manifiestan tan a menudo hacia nosotras. Rechazamos lo que los hombres tienen de machistas. Si no estuvieran cegados por las prebendas que obtienen de nuestra opresión, debieran de agradecernos que al luchar por liberarnos de sus cadenas, les estamos allanando el camino para que reflexionen y se rebelen también ellos contra la alienación que supone la condición de hombre en esta sociedad (LA REPÚBLICA DE LAS MUJERES, 10 de diciembre, 1988, p. 9).
\end{abstract}

La preocupación por el machismo de los compañeros políticos y de los espacios partidarios fue in crescendo a medida que transcurrieron los años y fue cambiando el clima de época. Las pocas oportunidades para el feminismo quedaban en evidencia en las distintas instancias decisorias del ámbito partidario, tanto en los congresos como en las campañas electorales y las elecciones generales. Las primeras elecciones de 1985 mostraron lo cerrado que era aquel espacio, situación que se reiteró para 1989, aun cuando se hubiera dado un gran crecimiento del feminismo, de su visibilización y de la cuestión de la mujer como tema de agenda. Las elecciones de 1989 finalizaron con siete diputadas electas, una presencia insuficiente y presentada como “manipulada” (LA REPÚBLICA DE LAS MUJERES, 21 de enero 1989: 6). Las elecciones de 1989 parecían confirmar el retrato que Fany Puyesky realizó irónicamente, más de una vez, sobre el Parlamento: otro Club de Toby, "un guetto de hombres".

¿Recuerdan al gordito Toby, el amigo de la pequeña Lulú? Él había formado su club de amigos en el bosque, donde no se admitían damas. (...) Sabemos que los hombres necesitan estar solos en sus clubes privados, en los campamentos, en los boliches de copas, etc. Necesitan huir de la mirada femenina, sentirse lejos del control materno, reafirmarse y confirmarse entre iguales, para hacer las cosas que mami (y la mujer que han elegido que casi siempre es una sustituta de mami) no les ha permitido hacer (...) Que se reúnan para huir de 
las mujeres, para contarse mentiras, para alabarse mutuamente, para decir palabrotas o para comilonas, se lo toleramos como buenas y comprensivas mamás. Pero que lo hagan para gobernarnos y manipularnos, no. (...) No sólo a las mujeres quieren gobernar sino a todos los que no son como ellos, es decir a aquellos que no constituyen la gerontoburomachocracia (MATE AMARGO, $\mathrm{N}^{\circ} 27,1988$ ).

En Cotidiano, en 1989, Lupe Dos Santos señaló el cansancio de luchar en una izquierda que no les daba lugar y, aunque no anunciaba el retiro de la militancia, sí sugería cierto fin de ciclo para las "mujeres de izquierda /militantes de segunda":

\begin{abstract}
Nos vemos enfrentadas una y otra vez a la ironía descalificadora, la soberbia de un poder, la ideología masculina. (...) nos cansamos de las exclusiones y de hacer papeles secundarios en las películas y vemos por suerte para la salud de cualquier organización- la incoherencia ideológica que significa luchar contra los opresores para repetir dentro de los partidos y organizaciones la discriminación hacia las mujeres. Porque nos cansamos de hombres que luchan a brazo partido contra la injusticia y en sus casas reproducen los roles burgueses más recalcitrantes que combaten (COTIDIANO, Año II, N 31, marzo 1989, p. 7).
\end{abstract}

Para fines de los ochenta la denuncia del autoritarismo se expandió hacia las comisiones de mujeres en la propia izquierda, una izquierda autoritaria, con "esquemas", con "cocinas", con "autoritarismos", como señala el documento de las feministas del PCU, dominada por lo que llamaban una "ideología masculina" ("Al fin todos estamos hablando de politica", s/f, Firman: Silvia Rodríguez Villamil, Alma Espino, Graciela Duffau, Nadia Delgado, Victoria Szchumacher, Celia Ruiz). En Cotidiano, en una nota titulada "La hipocresía sexual de la izquierda uruguaya", Garrido sostuvo que la izquierda estaba compuesta por hipócritas, quienes alimentaban un doble discurso e impedian politizar la sexualidad. Entre estos hipócritas, claramente los hombres, estaban aquellos que condenaban la prostitución y eran "clientes en las esquinas", y quienes reivindicaban la legalización del aborto pero en campaña electoral preferian "no agitar las aguas" (COTIDIANO, Segunda Época, $N^{\circ} 1$, noviembre 1990, p. 26).

El enojo, el cansancio y la decepción del feminismo con los espacios partidarios fueron acumulativos y claramente tuvieron su mayor expresión en el marco de otros acontecimientos de mayor escala que hicieron a un clima de crisis o desafección hacia la izquierda. Entre 1989 y 1992 se sucedieron una serie de hechos críticos que van desde la imposibilidad de derogar la Ley de Caducidad, pasando por la ruptura del Frente Amplio, la caída del Muro de 
Berlin y la crisis del PCU, hasta la derrota de Nicaragua en 1990. Todos ellos fueron factores de alejamiento respecto a la izquierda partidaria y generaron descreimiento sobre la transformación desde las instancias tradicionales. Sin embargo, cabe recordar que el cansancio y las criticas feministas a la izquierda partidaria comenzaron con anterioridad a estos eventos.

Ciertos temas o agendas no conseguian ingresar a la izquierda partidaria ni ser comprendidos desde la perspectiva feminista, y ciertas prácticas políticas parecían asfixiantes. Mientras que los primeros años de la segunda mitad de la década del ochenta estuvieron caracterizados más por una lógica cercana al partido, es decir, por prácticas de la política partidaria y por el deseo y las expectativas de participar, apoyar o incidir allí; los últimos años reflejan una transformación o al menos la inquietud por realizar una revisión crítica y el deseo o la necesidad de recostarse en una práctica más de hermandad entre mujeres. La necesidad manifiesta de juntarse entre mujeres y en espacios o desde prácticas más amigables que las tradicionales de los partidos tuvo cada vez mayor apoyo. Una señal de este proceso es el cambio de denominación de "seminario" o "congreso" por "encuentro".

A principios de los noventa, el feminismo cooperador o bien comportado en versión uruguaya parecía haber encontrado sus límites. Las emociones adquirian un protagonismo mayor, desde el enojo explícito hasta la burla con los espacios o las propias prácticas políticas. Un folleto de 1990 convocaba a la reunión de aquellas mujeres que se sentian hartas. En mayúscula el término "HARTA" se reiteraba de forma constante en varios interrogantes planteados en la convocatoria:

\begin{abstract}
¿No estás harta de pensar y pensar en los demás y nunca poder detenerte a pensar en vos misma? ¿Y de trabajar tanto y ganar tan poco? ¿De aguantar gritos, exigencias, agresiones? ¿No estás harta de que haya tantas mujeres violadas? ¿Y de tantas groserias en la calle? ¿De pensar qué vas a cocinar hoy y con qué lo vas a hacer? ¿No estás harta? ¡Y de que la TV te use para vender cigarrillos, whisky y productos que casi nunca podés comprar? ¿No estás harta de enfermarte cuidando la salud de los demás? ¿Y de tener que abortar clandestinamente? ¿Y de decidir cosas chiquitas y no estar nunca en las grandes decisiones? ¿NO ESTÁS HARTA DE ESTAR TAN HARTA? (ASAMBLEA NACIONAL DE MUJERES, 22 y 23 septiembre 1990. Coordinación de Mujeres. 1990, Folleto)
\end{abstract}

En 1989 se realizaron las segundas elecciones generales posdictadura. El feminismo de izquierda transitó hacia ellas con mucho más desilusión y cansancio que en 1985. Los medios de prensa feministas como La Cacerola, 
Cotidiano y La República de las Mujeres cubrieron la agenda política de las elecciones, pero también señalaron una y otra vez las dificultades que las mujeres tenían en los espacios partidarios, poniendo en cuestión por primera vez si valía la pena destinar energías a aquellos. Los resultados electorales no pudieron revertir este clima, sino todo lo contrario: ni una mujer electa como senadora y apenas siete diputadas.

A principios de los noventa se desintegraron las comisiones de mujeres dentro de los partidos, como ocurrió con la Comisión de Mujeres del PCU y la del PVP, o dejaban de funcionar por falta de integrantes, como la Comisión de Mujeres del Frente Amplio y la Comisión de Mujeres del PIT-CNT. Para quienes tenian como principal espacio de militancia feminista a la Comisión del PITCNT, del Frente Amplio o de los distintos grupos partidarios, la desintegración de estos espacios implicó el vaciamiento casi total de los lugares en los que desplegar el feminismo. Si bien el impacto más importante en el alejamiento lo tuvieron los espacios partidarios y sindicales, esto también afectó a las organizaciones sociales feministas, ya que las dobles militantes no sólo se alejaron de los espacios partidarios sino también de los sociales.

Se fue procesando un repliegue que implicó un alto grado de desmovilización y el ingreso a una etapa de invisibilidad del feminismo durante los noventa. Sin las organizaciones de masas ni los partidos, algunas se fueron para la casa y desde ahí tramitaron un proceso que podría caracterizarse como de resiliencia. Este es el caso de aquellas que fundaron el Frente Gastronómico Feminista (F.G.F.), un espacio absolutamente informal en el que se reunían no más que diez feministas que habían pasado por el PVP y el PCU, a comer y sociabilizar. Pese a no tener ninguna pretensión de intervenir en lo público, sino de ser un espacio nada más que de intercambio personal, igualmente se denominaba como "frente" y "feminista". El esplendor de su nombre, la estructura organizacional y el lenguaje utilizado en las comunicaciones internas evidencian que todas las formalidades de las prácticas políticas de la izquierda podían ser objeto de ironía.

Esta fue una experiencia más que puntual, informal y en el más absoluto registro del mundo privado, sin pretensión de intervención pública, pero que igualmente resulta un evento significativo para comprender la experiencia de las mujeres feministas del campo de la izquierda. El F.G.F. da 
cuenta de la necesidad de reunirse por fuera de los tan mentados espacios mixtos que terminaron siendo asfixiantes. De contar con un espacio específico y legitimo para la socialización y el intercambio entre mujeres, necesario para todas $^{13}$, y especialmente para la izquierda según la cual la ética del sacrificio aún sobrevivia. Espacios necesarios para intercambiar libremente, conversar de lo personal, reírse y "chusmear", como se decía en una de las comunicaciones, algo desprestigiado por la sociedad en general y fundamentalmente por la izquierda.

El F.G.F. también da cuenta del cansancio de las prácticas y los lenguajes tradicionales de la izquierda, las estructuras organizativas con autoridades, los discursos grandilocuentes, los modos de intervención en lo público, entre otros aspectos. Dice mucho sobre la relación con la izquierda porque es irreverente; se rien de ella, aunque dentro de ciertos límites. Ese espacio no es visualizado como otra forma de la praxis feminista, no aparece representado como un lugar de reflexión sobre las tareas reproductivas, en donde se politiza el mundo doméstico, la cocina y la transmisión generacional entre mujeres de los conocimientos culinarios.

El F.G.F. expresa la búsqueda de un refugio, de un lugar protegido, de sororidad para expresarlo en los términos actuales. Finalmente habian regresado a la cocina, pero lo habian hecho cambiadas: ahora regresaban como feministas, podian entonces disfrutar de la cocina y las comidas, podían darse el lujo de convocarse a "chusmear" y a elaborar comidas sin la misoginia de los compañeros y sin poner en riesgo su emancipación; esta ya había ocurrido. La duda que quedaba era entonces desde dónde construir el feminismo de izquierda para quienes aún no habían transitado por ese camino, si acaso las organizaciones partidarias no lo habian alojado ni lo alojarian, si las organizaciones sociales perdian a sus interlocutores/as dentro de las primeras y si la micropolitica de los hogares aún no era visualizada más que como una simple micropolítica.

Este fue un desafio más que complejo para un feminismo que había nacido al calor de la recuperación democrática, desde la voluntad de recuperar los canales tradicionales de la participación política e impulsado por una

\footnotetext{
13 Seminara y Viano (2009, p. 84) señalan cómo las mujeres no cuentan con espacios de socialización, como sucede con los hombres y los tradicionales asados.
} 
generación de feministas con una trayectoria militante en el campo de la izquierda. Transitar hacia una práctica de la "autoconciencia" inspiradas en el "consciousness-raising" 14 del feminismo radical en Estados Unidos, nacido también del cansancio de las lógicas masculinas de los grupos de las izquierdas (Hanisch, 1969), en aquel momento no fue para nada una tarea sencilla.

\section{Apuntes finales}

En 1984, la feminista chilena Julieta Kirkwood, una referencia para el feminismo del Cono Sur, publicó su ensayo titulado "Feministas y Políticas". En aquel texto que partía de una dicotomía arbitraria pero a la vez vigente, Kirkwood reflexionaba sobre los espacios y las prácticas para la intervención feminista. Señalaba las dificultades para la legitimación política de los espacios de mujeres, los espacios no-mixtos como se decía en la época, y la politización de temas asociados al registro de lo personal por un lado, y las dificultades de los espacios más vinculados a la politica tradicional para generar un nivel de profundización que permitiera ir a las raíces de la opresión. A esta tensión se sumaba la trayectoria de quienes desplegaban las prácticas feministas las cuales arribaban a esta nueva causa con un repertorio de prácticas heredadas y por tanto naturalizadas. La estrategia del feminismo se bifurcaba en dos opciones:

"una) Defender lo propio. Cerrar, cerrarse en encuentros reducidos, exclusivos feministas, donde pueda avanzar en la elaboración de una política, de unas estrategias y de unas tácticas.

Otra) No caer en el grupo cerrado y getto: amplitud de la convocatoria y la llegada a muchas mujeres que conjuguen los verbos dialogar, polemizar, participar.. Correr los riesgos de toda amplitud (acaso no era yo una de ellas?)" (KIRKWOOD, 1984, p. 19).

Como Kirkwood, muchas feministas de izquierda en Uruguay realizaron ese proceso, el de apostar a la amplitud, llegar "a las otras" y crecer, para luego considerar esta estrategia desde una mirada crítica. No rechazándola de forma absoluta, pero sí asumiendo los costos, los costos de

\footnotetext{
14 Reunidas en un pequeño grupo de no más de diez integrantes, las participantes elaboraban una reflexión a partir de las experiencias, las cuales permitian construir un conocimiento genuino, no mediado por teorias y generalizaciones abstractas androcéntricas. Las mujeres debian revisar su propia experiencia y construir desde ahí el conocimiento para luchar contra la opresión antes de luchar por "otras mujeres" (Sarachild, 1978).
} 
la profundización del debate de ideas y de la discusión feminista, y también los costos personales. Esta lectura crítica sobrevino una vez que los resultados de ese esfuerzo hacia la amplitud resultaron muy poco reconfortantes. A pesar del feminismo bien comportado, la reacción fue inmediata y la consigna "democracia en el hogar", desoída y silenciada.

Un grupo de mujeres lideraron la concientización, pero no construyeron un gueto feminista alejado de la "realidad" de las mujeres sino, por el contrario, desplegando una práctica insistentemente orientada hacia "afuera" y por lo tanto muy poco hacia "adentro", es decir, hacia ellas mismas. No se constituyeron en una élite feminista alejada de los sectores populares pero su estrategia implicó un gran esfuerzo no reconocido, ni siquiera percibido por la izquierda, que redundó en un desgaste que debilitó a aquellas pocas "feministas fuertes".

La gran política, hacia donde se canalizaron las mayores energías, ofreció escasas oportunidades para el feminismo: las expectativas sobre la ampliación de una democracia sustantiva y la renovación de la izquierda resultaron frustradas. A pesar de toda la estrategia cooperadora hacia el Estado y los partidos, el feminismo de izquierda fue muy poco escuchado. La democracia y la izquierda partidaria pasaron de ser consideradas oportunidades y pasaron a ser estructuras canceladoras de rebeldía. De la alegría y de la fiesta se pasó al hartazgo, que sin saber muy bien cómo procesarlo produjo un vacío sin el cual posiblemente no podría haber surgido otro momento refundacional.

El feminismo actual toma otra distancia respecto de la izquierda, pero aún no logra desplegarse ni pensarse del todo sin sus ideas y sus prácticas. La historia reciente de la relación entre izquierda y feminismo se torna entonces un elemento imprescindible también para comprender la "revolución de las pibas" o la "nueva primavera feminista". El enojo, la irreverencia, las impugnaciones a la politica tradicional, a la palabra escrita y a la teoría, el descrédito respecto al Estado y partidos, la consideración de la democracia como un mero mecanismo fagocitador hoy son las marcas identitarias de un feminismo mucho menos dispuesto a la cooperación, que parece haber incorporado, aunque no lo enuncie, la experiencia agridulce de sus antecesoras. 


\section{Bibliografía}

ÁLVAREZ, S. Feminismos Latinoamericanos. Estudios Feministas. Vol. 6 (2), pp. 265-284, 1998.

COSTA, A. E viável o feminismo nos trópicos? resíduos de insatisfação - São Paulo, 1970. Cadernos de Pesquisa. (66), pp. 63-69, 1988.

CUADRO, I. Feminismos y Politica en el Uruguay del Novecientos. Internacionalismo, culturas politicas e identidades de género (19061932). Montevideo, Uruguay: Banda Oriental, 2018.

DE GIORGI, A. L. Entre la lucha contra la carestía y por los derechos de la mujer. Las comunistas uruguayas durante la segunda mitad del siglo XX (1942-1973. En Valobra y Yusta (eds.), Queridas camaradas Historias iberoamericanas de mujeres comunistas, (pp.215-234.). Buenos Aires, Argentina: Miño y Dávila, 2016.

DE SOUZA, G. Resistência, solidariedade e rebeldia: o feminismo das mujeres creando na Bolivia (1992-2015). (Tesis Doctoral en Historia). Universida Federal de Santa Catarina, Florianópolis, 2018.

ESPINOSA, Y. Escritos de una lesbiana oscura. Buenos Aires-Lima: En la Frontera, 2007.

FALQUET, J. Las feministas autónomas latinoamericanas y caribeñas: veinte años de disidencias. Universitas Humanística (78), pp. 39-63, 2014.

FELIÚ, V. ¿Es el chile de la post-dictadura feminista? Estudos Feministas, v. 17 (3), pp.701-715, 2009.

FISCHER, A. Los caminos complejos de la autonomía. En Curiel O. FALQUET, J. Y MASSON, S. Feminismos disidentes en América Latina y el Caribe. Nouvelles Questions Féministes. v. 24, pp. 54-78, 2005.

GARGALLO, F. Feminismos desde Abya Yala. Ideas y proposiciones de las mujeres de 607 pueblos en nuestra América. Ciudad de México, México: Universidad Autónoma de la Ciudad de México (UACM), 2014.

HANISCH, C. "Lo personal es politico", Ediciones Feministas Lúcidas, traducción libre Insu Jeska. Recuperado de Versión en español: <http:/ / autonomiafeminista.cl/lo-personal-es-politico-2/>

JOHNSON, N. The right to have rights: gender politics, citizenship and the statein Uruguay (Thesis Political Science). Department of Political Studies, Queen Mary and Westfield College, University of London, 2000.

LEIBNER, G. Nosotras (Uruguay, 1945-1953): Las contradicciones de la escritura femenina comunista y sus significados sociales. En FORGUES, R. Y FLORES, J. (eds.) Escritura femenina y reivindicación de género en América Latina. Paris, Francia: Mare \& Martin, 2004. 
LESGART, C. Usos de la transición a la democracia: Ensayo, ciencia y política en la década del 80. Rosario, Argentina: Homo Sapiens Ediciones, 2003.

MOYANO, C. La retórica de la renovación hasta su paroxismo: del MAPU renovado al Lautaro. Revista de Historia Social y de las Mentalidades. Año XII, Vol 2, pp. 123-147, 2008.

NAVARRO, M. El primer encuentro feminista de Latinoamérica y el Caribe. En LEÓN M. (ed.) Sociedad, subordinación y feminismo: Debate sobre la mujer en América Latina y el Caribe: Discusión acerca de la Unidad ProducciónReproducción, Vol. III., pp. 261-266, Bogotá, Colombia: Asociación Colombiana para el Estudio de la Población, 1982.

OLEA, C. (comp.). Encuentros, (des) encuentros y búsquedas: El movimiento feminista de América Latina. Lima, Perú: Ediciones Flora Tristán, 1998.

PEDRO, J. Narrativas do feminismo em países do Cone Sul (1960-1989). En PEDRO, J. Y WOLFF, C., Gênero, feminismos e ditaduras no Cone Sul, pp. 115-137. Florianópolis, Brasil: Editora Mulheres, 2010.

REMEDI, G. Transiciones/traslaciones: recorrido personal y ensayo retrospectivo de los estudios literarios en los 80. En DEMASI, C. Y DE GIORGI, A. (comps), E1 retorno a la democracia: otras miradas (pp. 169-197). Montevideo, Uruguay: Fin de siglo, 2016.

RESTREPO, A. Tras los rastros del proyecto sociopolitico feminista: Encuentros Feministas Latinoamericanos y del Caribe -1981-2014 (Tesis Doctoral). Universidad Nacional Autónoma de México, México, 2016.

RIVERA, E. El grupo editorial La correa feminista y su relación con el movimiento feminista autónomo en México (Tesis de Maestría). Programa Interdisciplinario sobre Estudios de la Mujer, Colegio de México, 2009.

SEMPOL, D. Transiciones democráticas, violencia policial y organizaciones homosexuales y lésbicas en Buenos Aires y Montevideo (Tesis Doctoral en Ciencias Sociales). Universidad General Sarmiento, Buenos Aires, Argentina, 2014.

STERNBACH, N., NAVARRO M., CHUCHRYK, P. Y ÁLVAREZ, S. Feministas na América Latina: de Bogotá a San Bernardo. Estudos Feministas. V. 2, pp. 255-295, 1994.

TORO, S. Debates feministas latinoamericanos: Institucionalización, autonomía y posibilidades de acción política (Tesis Maestría en Estudios Latinoamericanos). Facultad de Filosofia y Humanidades, Universidad de Chile, Chile, 2007 
VEIGA, A. M. Feminismos em rede? Uma história da circulação de discursos e informações entre São Paulo e Buenos Aires (1970 - 1985) (Tesis de Maestría en Historia Cultural). Universidade Federal de Santa Catarina, Florianópolis, Brasil, 2009.

VIANO, C. Voces (des-encontradas) en los Encuentros Nacionales de Mujeres en Argentina. Revista Digital de la Escuela de Historia, Año 6, V. 11, pp.4968, 2014. 